Technological University Dublin

\title{
Gamification of Icebreaking Activities for Mechanical Engineering Students Embarking on a Problem Based Learning Module
}

\author{
Kevin Delaney \\ Technological University Dublin, kevin.delaney@tudublin.ie \\ Gerard Nagle \\ Technological University Dublin, gerard.nagle@tudublin.ie \\ Mingzhu Chen \\ Technological University Dublin, mingzhu.chen@tudublin.ie
}

Follow this and additional works at: https://arrow.tudublin.ie/engineduccon

Part of the Computer-Aided Engineering and Design Commons, and the Other Engineering Commons

\section{Recommended Citation}

Delaney, K., Nagle, G. and Chen, M. (2021), Gamification of Icebreaking Activities for Mechanical

Engineering Students Embarking on a Problem Based Learning Module. INTED 2021, 8-9 March 2021. doi: 10.21125/inted.2021.2221

This Conference Paper is brought to you for free and open access by the Engineering: Education and Innovation at ARROW@TU Dublin. It has been accepted for inclusion in Conference papers by an authorized administrator of ARROW@TU Dublin. For more information, please contact arrow.admin@tudublin.ie, aisling.coyne@tudublin.ie,gerard.connolly@tudublin.ie.

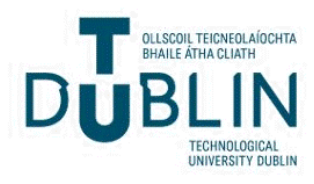




\title{
GAMIFICATION OF ICEBREAKING ACTIVITIES FOR MECHANICAL ENGINEERING STUDENTS EMBARKING ON A PROBLEM BASED LEARNING MODULE
}

\author{
Delaney, Kevin Dominic; Nagle, Gerard and Chen, Mingzhu \\ School of Mechanical and Design Engineering, Technological University Dublin (IRELAND)
}

\begin{abstract}
When they enter the workforce engineering graduates must be able to engage collaboratively with others to find solutions to complex engineering challenges. This involves a great deal more than simply solving technical problems traditionally taught in engineering school. The Mechanical Engineering Discipline in Technological University Dublin (TU Dublin) has helped students develop real-world engineering skills through a team based Problem Based Learning (PBL) module since 2005. This module, involving third year students, can be particularly challenging since participants can join the third year of the program from other programs or universities and many will not have known each other prior to taking the module. Coming to the module with different prior learning experiences these undergraduate engineering students must engage collaboratively with each other when they undertake the team-based design project.
\end{abstract}

Over several years the authors have developed an icebreaker game which encourages students to get to know each other. The session, conducted over three hours, welcomes the students and helps them comfortably interact with each other and with the facilitators. This paper describes the development of this activity through the integration of gamification design elements. It goes on to explain how the students must reflect on their experience in this session and how these reflections are then used to frame and scaffold their work for the rest of the module as they consider how to best plan, design, build, and test real machines within the constraints of a strict budget and time limit.

Keywords: Engineering education, gamification, game design elements

\section{INTRODUCTION}

Team based Problem Based Learning (PBL) has helped mechanical engineering students in Technological University Dublin (TU Dublin) develop real-world engineering skills since 2005 [1], [2]. The latest revision of this module, which is assigned five ECTS credits, is run over the course of an academic year during which students have 26 weekly sessions scheduled with the project facilitators. Students typically work in groups of five or six and self-select which classmates they will work with. Each group is assigned the task of designing, fabricating and sourcing all components for, assembling, and testing a robotic machine. Involving third year students, the module can be particularly challenging since students from a variety of backgrounds with different prior learning can join the third year of this program. Joining the third year from other programs or universities means many students will not have known each other prior to taking the module so the facilitators deliberately incorporate team building activities into the first project session each year.

These team building activities, developed as an icebreaker game by the authors over several years, are conducted during a three hour session, and aim to welcome the students and help them comfortably interact with each other and with the facilitators. Furthermore the session encourages students to demonstrate some basic technical and organizational skills and, perhaps more importantly, simultaneously forces them to recognize and reflect on the skills that they will need to successfully complete their engineering projects.

This paper describes how the icebreaking activities are built upon the principles of game design. It goes on to explain how the students, upon completion of this activity, reflect on their experience in this session and in doing so consider how they might alter their approach to best plan, design, build, and test their creations within the strict budget and time constraints. 


\section{BACKGROUND}

The word engineer derives from the Latin roots ingeniare ("to create, contrive, devise") and ingenium ("cleverness") [3]. Engineers typically design, analyse, build and test machines, structures and other systems whilst simultaneously considering and respecting constraints imposed by the specific application, practicality, safety and cost. In addition to discipline specific knowledge in the areas of science, maths, engineering analysis, design, manufacturing and engineering practice, common skills that employers expected of engineering graduates include:

1. Communication skills (both verbal \& written)

2. Teamwork and interpersonal skills

3. Creativity

4. Flexibility/adaptability

5. Analytical skills

These attributes align with the criteria outlined by Engineers Ireland who accredit mechanical engineering programmes within the School of Mechanical and Design Engineering [4]. It can be difficult to "teach" such skills to students since many do not respond strongly to instruction they may not perceive as engaging. One pedagogical approach which has been proposed to help engage such students involves the use of games. Educational games can provide students with a motivating and stimulating environment while providing them with immediate and appropriate feedback to promote learning.

Based upon the definition outlined by Crawford a game is an interactive, goal-oriented activity, with active agents to play against in which players (including active agents) can interfere with each other [5]. It has been suggested that Games-based Learning can enhance the student experience and learning process. This is the theory behind gamification; that incorporating game-like elements into activities can potentially make them more appealing and increase engagement levels. "Gamification" is difficult to define but generally refers to adding game-like elements into an activity that is not traditionally considered a game.

A significant number of publications recommend this approach across a wide range of subject areas. Bodnar et al [6] have conducted a systematic review of game-based learning within engineering. They reported that between 2000 and 2014, 191 papers were published on the pedagogical use of games or game elements in the undergraduate engineering classroom. Since more than half of these papers were published since 2010 they concluded that interest in the dissemination of results obtained by implementing games is increasing.

Examples of game approaches in engineering education include:

i. One-off games: These are designed to be completed in a single session. They are generally easy to set up, explain, play and debrief in a constrained timeframe.

ii. Badges/Points/Leader-boards: Referred to as the BPL approach, students are incentivised to learn required material or perform optional, extra tasks.

iii. Narrative Games: These games are where the class, or at least portions of it, has an overarching story. This consists of the plot, sounds, music, atmosphere, dialogues, player choices and, of course, gameplay. The story creates the overall impression of a game and allows the player to feel like part of a story. It serves to anchor the students and provide opportunities for engagement with the material.

The remainder of this paper describes a one-off game example which the authors have implemented each year over the last several years as the first session of a problem based learning module.

\section{GAME PROCEDURE}

Based upon time constraints within the overall module a one-off approach was deemed to be most appropriate when developing this activity. The focus is to present a resource-restricted challenge for students, the solving of which necessitates engagement and collaboration within their group. The work of each team has to be made available to an appropriate challenge by members of competing teams, essentially a form of peer review, in order to justify the bragging rights which the first placed team are entitled to, and certainly savour. Overall the priority of this session is to ensure that students have fun 
while learning and that they have the opportunity to reflect on how they could modify and improve their behaviour when facing future challenges.

The session starts with a brief overview of a typical engineering design process. Afterwards students are asked to form groups of 6 students for a mystery game activity. The game, which is summarised in Figure 1, starts immediately after the groups are selected and comprises the following:

A clear goal: each group must build the tallest free standing, stable, structure that they can using the resources supplied and within the allowable timeframe. The maximum footprint of the structure must be the same size as an A3 page. Each team, consisting of 6 members, is resourced with $4 \times A 3$ sheets, $10 \times$ A4 sheets and 5 paper clips.

Clear rules: Students must only use the resources that they have been given. Each team is given 45 minutes to deliver their solution to this challenge.

Interaction: Students must work together and remember that their work can be challenged by all other groups once complete, so they must ensure that their structure is very stable, not just the tallest. Once the allowable build time has elapsed students must make their structure available to challenge by other teams. The challenge takes the form of a single student from opposing teams blowing at any point of the structure they choose from a distance the equivalent of 1 A4 page length away. If the structure survives this "windy" condition the challenge from that team is deemed to have failed.

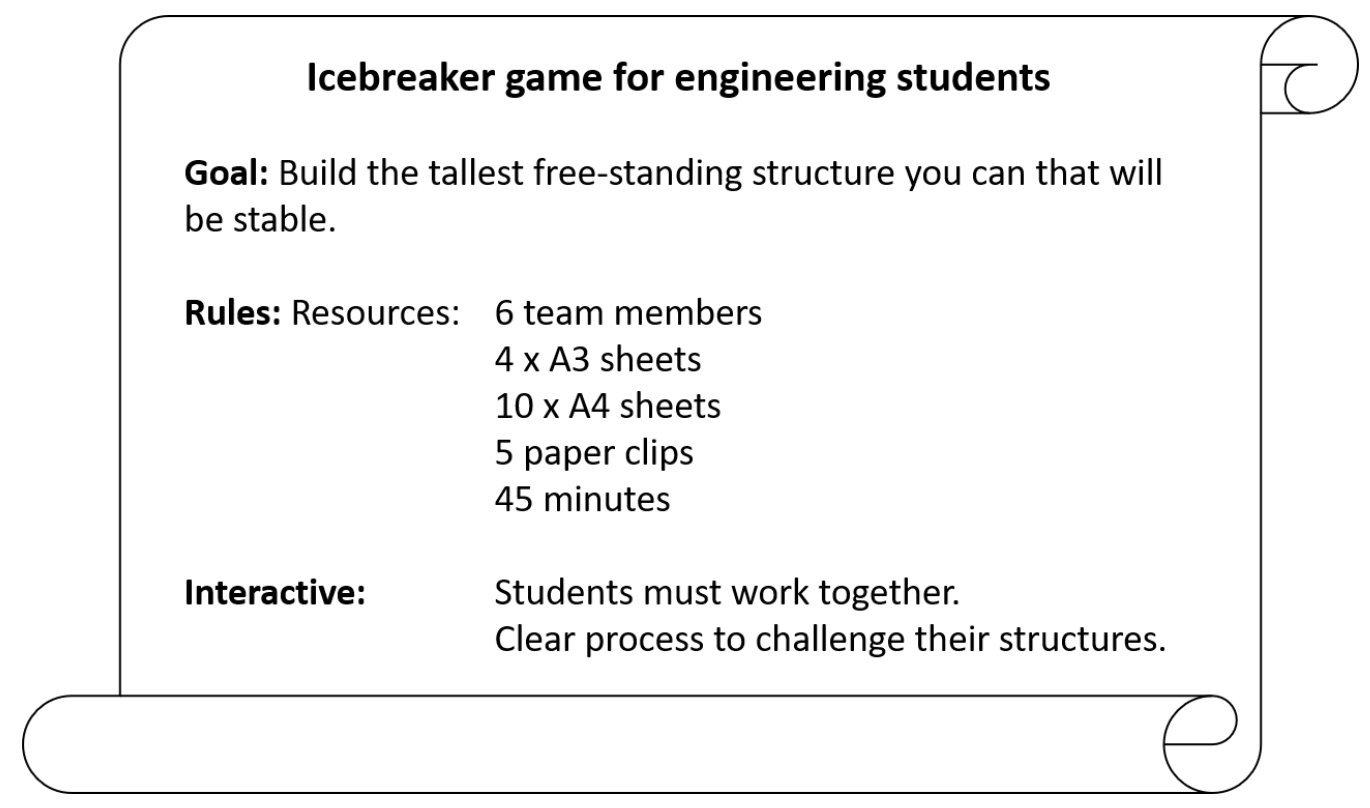

Figure 1: Summary overview of icebreaker game for engineering students

Initially this competition was run with newspapers and structures more than $3 \mathrm{~m}$ tall were created. Standardizing on a more limited range of materials (due to student feedback) has resulted in reduced overall heights and requires more planning and consideration prior to building as shown in Figure 2. Occasionally variants, such as providing a specific length of tape for each group, allowing them "trade" a clip for an A3 page or 2 A4 pages, have been introduced if facilitators feel that it's appropriate.

For safety reasons students must build their structures from the ground and members must not climb or stand on top of any furniture within the room used for the event. This is explained to students and introduces the importance of considering health and safety and conducting safety reviews. This thought process is developed further and formalized once students start to actually design their robots as the module progresses.

Students must also sort the materials used to create their structures for recycling. This is important as it forces students to consider the need to sort the materials and encourages them to consider sustainability as part of their overall design activities. 

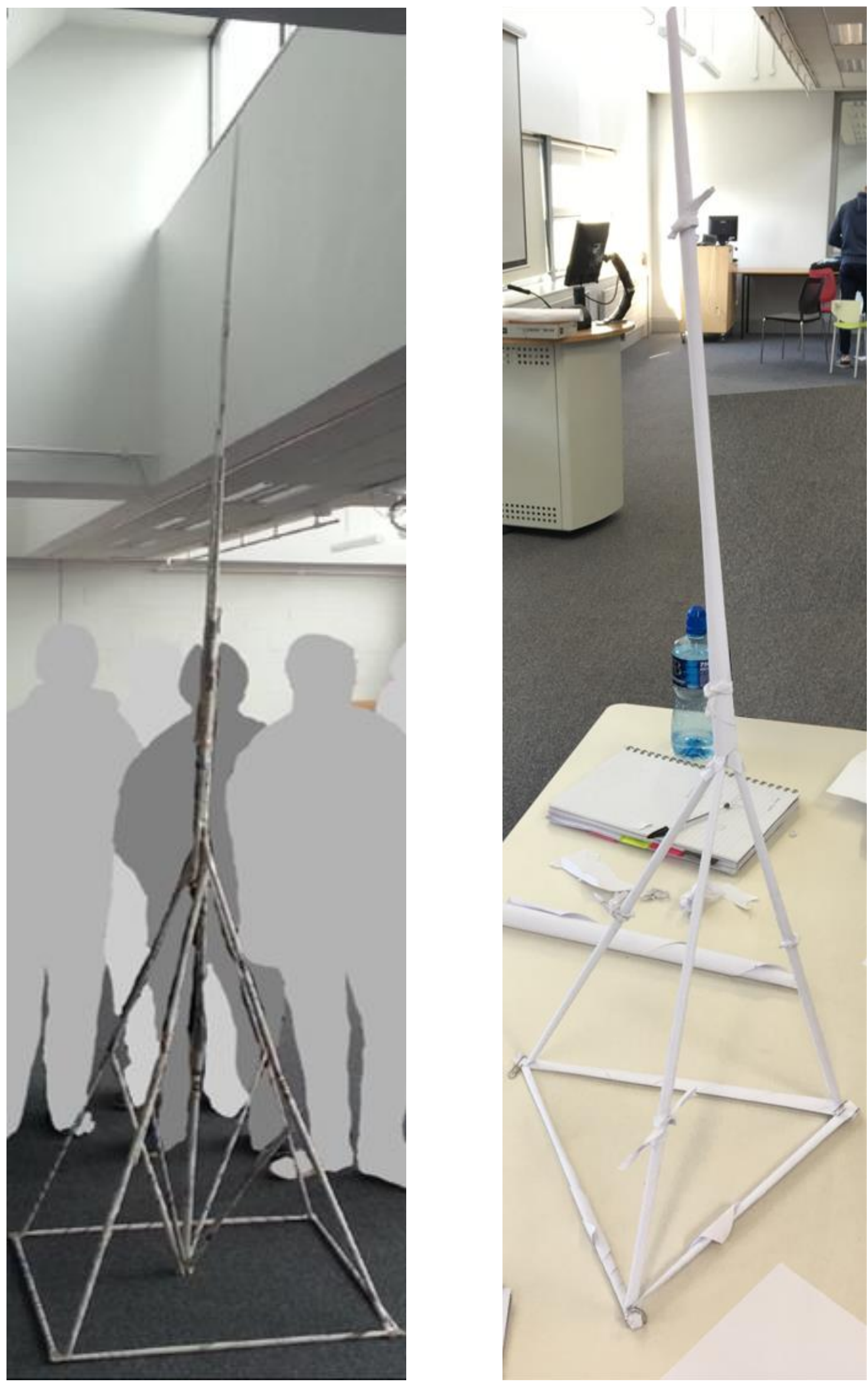

Figure 2: Examples of representative structures created over the last 10 years 


\section{REFLECTION PHASE}

Immediately after the design challenge game is complete each student group is challenged to reflect on their experience. They are asked to answer questions such as "What did they do that was positive?", "What did they do that was negative or counter-productive for the team?", "How would they improve their performance if asked to conduct a similar exercise in the future?". Each team is provided with a flip-chart upon which they can record their reflections. This reflecting process, often referred to as a debriefing in the literature, is considered to be an important part of game-based learning since it provides feedback to help learners reflect on their experience and understand how games can improve the overall effectiveness of their education [7]. In the context of this module it helps students develop meaningful connections between the icebreaking exercise described here and the learning that it can bring to the remainder of the module right into their future engineering careers [8]. Examples of typical responses received from student groups over the last several years are shown in Error! Reference source not found.

Table 1: Typical student groups comments after reflecting on their performance

\begin{tabular}{|l|l|}
\hline \multicolumn{1}{|c|}{ Team positives } & \multicolumn{1}{c|}{ Team negatives } \\
\hline Everyone got involved & Too ambitious with the size \\
\hline Good use of resources & Needed a stronger base \\
\hline Low centre of gravity & Should have brainstormed ideas more \\
\hline Good communication & Time management was poor \\
\hline Defined the problem well & Not enough sketching and planning \\
\hline Good use of prototype & Poor execution of design \\
\hline & Poor problem definition at the start \\
\hline & Distracted by competitors presence \\
\hline & Did not test enough \\
\hline
\end{tabular}

The flipchart sheets are retained by the lecturing staff at the end of the session. Prior to the second session, when the main PBL project kicks off, the module facilitators review these submissions and group the responses into specific thematic areas. At the very beginning of the second session these are highlighted to the students and coupled with appropriate advice, notes and other additional resources to help students develop skills in these areas. The primary objective is to encourage students to "follow their own advice" as they embark on their "real" engineering design project.

\section{CONCLUSION}

Icebreaking activities using Game Based Elements have been applied to this module over the last several years. These activities help students get to know each other and also reflect on and inform their approach to solving technical problems as part of a team. Student feedback to date has been overwhelmingly positive, with one student claiming that the session was "the most fun he had in engineering in over 3 years in the university".

One of the authors, Dr Chen, has a unique perspective in that he both facilitates students on the program and has previously undertaken the module as an undergraduate student. Based upon his recommendations the module is becoming more closely aligned and integrated with the electronics and control modules that the engineering students take.

Based on the authors' experience of undertaking and/or delivering the module since 2007 participating in this session is very important and beneficial for students. Reflecting on what went right/wrong for their team in solving a relatively simple engineering challenge with no credit at stake, coupled with guidance on how they might overcome common challenges such as time management, planning and applying a more systematic design process helps students become more effective problem solvers. More specifically it has resulted in graduates who can successfully demonstrate their ability to engage collaboratively with others to find solutions to complex engineering challenges and refine their realworld engineering skills, as demanded by industry. 


\section{ACKNOWLEDGEMENTS}

The ongoing support of the School of Mechanical and Design Engineering for this and other ongoing, aligned, activities is gratefully acknowledged.

\section{REFERENCES}

[1] K. Delaney, and J.B. Kelleher, "Real-World Process Design for Mechanical Engineering Students: A Case Study of PBL in DIT", 2008. https://arrow.dit.ie/engschmeccon/16

[2] K. Delaney, and G. Nagle, "Teaching Approximations of Mechanical Engineering Practice through Designing and Building Robots: An Approach Inspired by Monozukuri". WERA 2019,Tokyo (Japan) 5th-8th August 2019. doi:10.21427/3r4d-jx53

[3] International Association of Engineers. Retrieved January 8, 2021, from http://www.iaeng.org/about_IAENG.html

[4] Engineers Ireland. (n.d.). Accreditation requirements. Retrieved January 8, 2021, from https://www.engineersireland.ie/groups/students/accreditation.aspx

[5] C. Crawford, Chris Crawford on game design, Indianapolis, IN: New Riders Publishing, 2003.

[6] C.A. Bodnar, D. Anastasio, J. Enszer, and D. Burkey, "Engineers at play: Games as teaching tools for undergraduate engineering students," J. Eng. Educ., vol. 105, no.1, pp. 147-200, 2016.

[7] R.T. Hays. "The effectiveness of instructional games: A literature review and discussion," Naval Air Warfare Center Training Systems Division, 2005.

[8] S. Nicholson. (2012, March). "Completing the experience: Debriefing in experiential educational games," In Proceedings of the 3rd international conference on society and information technologies, pp. 25-28, 2012. 